\title{
Research on the Innovation of the College Students' Ideological and Political Education from the Perspective of Theory of Human's Comprehensive Development
}

\author{
Honglin Tang ${ }^{1}$ \\ ${ }^{1}$ Guangdong Mechanical \& Electrical Polytechnic, Guangzhou, Guangdong Province, China
}

Keywords: Theory of Human's Comprehensive Development; ideological and political education; innovation.

\begin{abstract}
Theory of human's comprehensive development is an important theory of Marx. To promote the innovation and development of the college students' ideological and political education from the perspective of this theory is an important part of higher education in the new period. Based on the basic connotation of Theory of Human's Comprehensive Development, this paper analyzes the characteristics of the college students' ideology and puts forward the innovative ways of the college students' ideological and political education.
\end{abstract}

\section{Introduction}

Being the contents of political stability and the cultivation of talents and social development, the ideological and political education of college students has been highly valued by the Party Central Committee. Marx's Theory of Human's Comprehensive Development is a theoretical basis for the innovation of ideological and political education. It focuses on the subjectivity of the people and regards it as the main body of social development. We analyze and organize the content of education and make reasonable adjustments to education from the main point of view. The effect is more obvious and more prominent. Strengthening the ideological and political education of the college students is the objective demand of the development of the times, as well as the important guarantee of the national political stability.

\section{The Basic Connotation of Theory of Human's Comprehensive Development}

To meet the demand. In Theory of Human's Comprehensive Development, meeting the needs of human being is one of the basic contents and conditions. Because human's behavior generally has certain purpose and are closely related to people's needs [1]. However, people's needs are not stationary. Their needs dynamically change. According to the social background, the situation of the people and other specific factors will change. Human are complex individuals whose complexity is determined by many factors. In the face of complex individuals and the complex social context, meeting the needs of people will be more difficult. With the development of social economy, people's ideology has undergone changes. Their needs are not limited to the material level. They prefer to spiritual development. Therefore, in the background of the new situation and era, the comprehensive development of people needs will meet the diverse needs of people.

To rich social relations. Human beings are the main body of social relations. The existence of human beings has formed various forms of social relations. And the status of social relations will affect the existence and the development of human beings. Generally speaking, if a person's social relations are more abundant, the relationship between him and others and various social factors will be simpler. The social productive forces and social division of labor are increasingly elaborate. In this background, people will develop from a natural community to a social community in social communication. Thus, they can continuously enrich and promote their continuous improvement and development from the perspective of social relations.

To freely develop personality. Different people have thinking and congenital physiological structure. Thus, they will have different personality, which is an obvious sign of differences between individuals. As for the comprehensive development of human beings, it is necessary and practical to 
find a unified development rule to promote the free development of each individual. In the free development of personality, it is very important to have a correct view of one's personality. Respecting for human personality development does not mean blindly indulge each individual. It should be conformed to the social background and premise, which is based on the most basic moral requirements. If we are out of the bottom line and requirements, personality will become a disorder, which is not conducive to the development of talent cultivation and social development.

To play the role of subjectivity. For social practice, people are the main body. To make people fully meet the demand, we should make people's subjective initiative, creative, initiative and make the consciousness effective. Among these characteristics, the basic and starting point is the subjectivity of the people. If a person's subjectivity has been well developed, his or her main force will have effective, which will promote the overall improvement of human beings.

\section{The Characteristics of College Students' Ideological and Political Education in the New Period}

Diverse ideology. With the development of society, the network is more and more developed. Under the impact of the developed and diversified network culture and information, the college students' values have also been diversified. On the one hand, the network itself is convenient for people. On the other hand, it gives bad information to people. From the perspective of the distribution of network information in the world, some western countries occupy most of the information, including The Associated Press and Reuters which are the main body. The college students have less social experience. Their discrimination ability is not strong. Therefore, they cannot distinguish good information and bad information. And they may be influenced by the network. Thus, they may form a plurality of values in the context of network information.

Utilitarian value orientation. The continuous economic development has led to the rapid development of the commodity economy era. In such an increasingly era with rich material, the college students' living conditions are getting better and better. Under the impact of different social thoughts, the value orientation of the college students has been greatly changed and it tends to be utilitarian. In the current context, many college students pay more attention to money and material enjoyment. They regard the material as a measure of quality standards and form serious commercialism and hedonism. They excessively pursue the material enjoyment, emotional indifference and lack social morality.

Unitary practice. In universities, the courses of ideological and political education are generally theoretical courses. Most of them lack the appropriate course of practice. Therefore, it is difficult to make the students feel the application of theory in life and promote the students' improvement and growth-up in practice. Although some universities and colleges have also carried out a variety of second classroom activities, these activities often lack a core idea, making the development of activities less effective to enhance the students' practical ability.

The dominant position of marginalization. Although each university carries out the ideological and political education in accordance with the relevant requirements, most of them regard it as a political task instead of carrying out from the perspective of the students, which makes the actual demand of education and the students separated, makes the students' main position less prominent and reduces the teaching effect.

Complex personality development. With the complexity of the development of the social production environment, the individual development of the college students becomes more and more complicated. Due to the influence of material life, their money worship, individualism and hedonism are becoming increasingly prevalent. At this stage, our country needs the innovative talents. Therefore, how to realize the complex personality development is the problem of the college students' ideological and political education. 


\section{Theory of Human's Comprehensive Development and the College Students' Ideological and Political Education}

The comprehensive development of human being is the purpose of college students' ideological and political education. Theory of Human's Comprehensive Development is to realize the college students' comprehensive development, which is consistent with the needs of society for talents. The development of ideological and political education of college students should be carried out from the perspective of the needs of the society and the country, as well as the students' situation. Therefore, the students' comprehensive development is the purpose of ideological and political education [2].

College students' ideological and political education can promote their comprehensive development. The comprehensive development of human being is not a slogan. It requires supporting. Ideological and political education is a platform for the comprehensive development of human beings. Universities and colleges can use this platform to educate and guide the college students to realize the students' comprehensive development.

\section{Theory of Human's Comprehensive Development Can Guide the College Students' Ideological and Political Education Innovation}

To scientifically set the college students' ideological and political education. The ideological and political education of college students has a clear goal, which is different in different times and is based on the development of the times. The scientific goal of the ideological and political education is the focus of the current ideological and political education. The rational goal can better promote the college students' comprehensive development. In the specific target setting, the universities and colleges should comprehensively consider from many factors and constantly adjust and research. Blindly conservative will make the education lose the practical significance [3].

To establish the people-oriented education philosophy. The object of education is human. The individual difference determines that it is difficult for education to be consistent. Because this kind of education is not conducive to the development of the college students. The people-oriented educational philosophy emphasizes the students' subject status, which is in accordance with Theory of Human's Comprehensive Development. At the same time, the human's development can promote the development of education, making the education pertinence and effect more prominent.

To focus on the college students' requirements. From Marx's Theory of Human's Comprehensive Development, it is found that the college students' ideological and political education should be based on their requirements. We should fully understand and respect the students and meet their legitimate requirements. Due to the college students' different growth backgrounds, their requirements are different. It is an important problem for the ideological and political education for college students to meet their different needs. Thus, we can protect their individual development and meet the needs of common development. To better meet the needs of college students is engaged in ideological and political education. The workers should pay attention to this problem. In the specific practice, we should understand and analyze the needs of college students from a scientific point of view, which will promote the development of teaching and education and completes a good docking between them.

To enrich the social relations of the college students. With the continuous development of society, the relationship between the university and the society is closely linked, which is the base for the development of the social needs of personnel training, as well as the core of scientific research and social development and Chinese culture [4]. In social relations, the ideological and political education should focus on the social development and the training of social talents who are required by the social development. It should be carried out to from the perspective of service, so that the ideological and political education can enrich the students' social relationship in the process of education development. The education guidance from the comprehensive the development of the overall point of view can improve the students' comprehensive quality. 
To focus on the college students' personality development. The compound talents are demanded by our society. Therefore, the cultivation of talents in universities and colleges should be from the perspective of the students' personality development. The ideological and political education workers should pay attention to the students' personality development. The core of personality is to create spirit. Therefore, we should pay attention to the cultivation of the students' creative thinking.

To emphasize the college students' subjectivity. College students are the main body of ideological and political education. Only their subjectivity is fully realized in education, can the education show its influences. The college students' subjectivity is the basis of ideological and political education, as well as a prerequisite for the effective education. Therefore, it is an effective way to stimulate the demand of the students' subjectivity and guide them to play their rolein the ideological and political education in universities and colleges.

To promote the college students' comprehensive development. In the background of the demand for complex talents, promoting the comprehensive development of college students' ability is a basic condition and requirement [5]. Based on Theory of Human's Comprehensive Development, the development of human should be comprehensively carried out, which not only has the comprehensiveness of ideology and social relations, but also includes the comprehensiveness of the college students' ability. The ideological and political education is an ideological education. It can influence the college students' behaviors with their ideological level. Therefore, it can promote the students' all-round development under the functions and influences of their own subjectivity.

To strengthen the cultivation of college students' practical ability. In the past, the college students' ideological and political education was mainly carried out in the form of theoretical education. However, the boring lecture forms could not arouse the students' interest in learning. It even caused certain psychological conflict. In Theory of Human's Comprehensive Development, the cultivation of the college students' ideological and political education should also focus on their practical ability. We should find out the reality supporting for the theory, so as to promote the ideological and political education.

\section{Conclusions}

To sum up, human's comprehensive development is the goal of talent cultivation. Based on Theory of Human's Comprehensive Development, the innovation of the college students' ideological and political education is an important task of our country's higher education in the new era.

\section{References}

[1] Yan Wu. Applications of Marx's Theory of Human Comprehensive Development in College Students' Ideological and Political Education [J]. Journal of Hubei University of Science and Technology, 2014 (11): 64-65.

[2] Xiu-chao Li. Enlightenments of Theory of Human's Comprehensive Development on College Students' Ideological and Political Education [J]. Journal of Hubei Correspondence University, 2014 (11): 47-48.

[3] Wei Song. College Students' Ideological and Political Education from the Perspective of Marx's Theory of Human's Comprehensive Development [J]. Education and Vocation, 2014 (35): 63-64.

[4] Ying Han. Comprehensive Human Development and College Students' Ideological and Political Education [J]. Journal of Jilin Agricultural Science and Technology College, 2015 (03): 43-45.

[5] Jian-hua Bo \& Jing Sun. On the Innovation of Ideological and Political Education from the Perspective of Theory of Human's Comprehensive Development [J]. The Party Building and Ideological Education in Schools, 2016 (05): 16-18. 